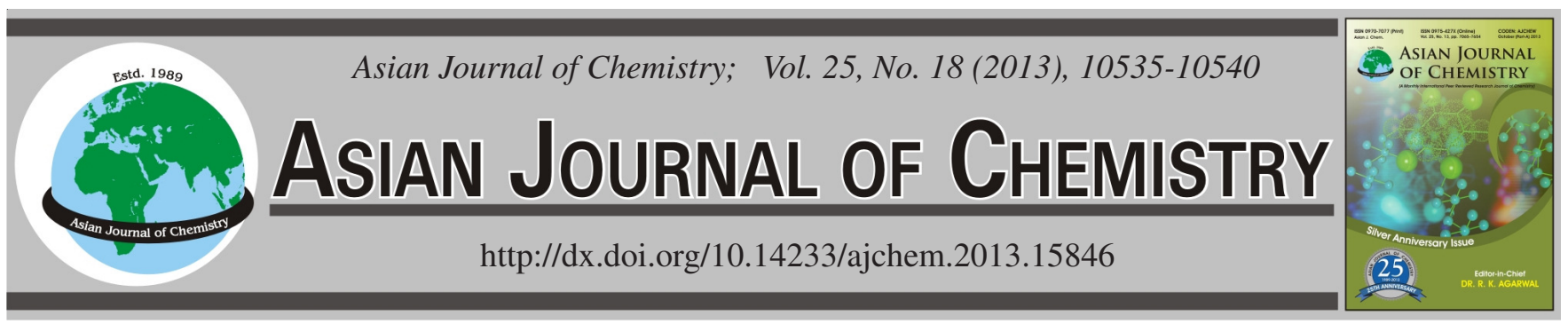

\title{
Covalent Self-Assembly of Multi-Walled Carbon Nanotubes and Gold Nanoparticles for Detecting DNA Sequences of Genetically Modified Corn
}

\author{
Li Tian ${ }^{1}$, Jimei Zhang ${ }^{1, *}$, GuangPing Chen ${ }^{1}$, Ying Li $^{1}$, Shibo QI ${ }^{2}$ and $\mathrm{Li} \mathrm{Li}^{2}$
}

${ }^{1}$ State Key Laboratory of Hollow Fiber Membrane Materials and Processes, School of Environment and Chemical Engineering, Tianjin Polytechnic University, Tianjin 300387, P.R. China

${ }^{2}$ Department of Physiological Sciences, Center for Veterinary Health Sciences, Oklahoma State University, Stillwater, Oklahoma 74078, United States of America

*Corresponding author: Fax: +86 22 83955451; Tel: +86 22 83955167; E-mail: toby509@163.com; zhangjimei6d311@ 163.com

Key Words: DNA biosensor, Multi-walled carbon nanotubes, Gold nanoparticles, Genetically modified organism.

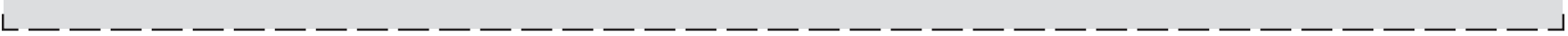

\section{INTRODUCTION}

Transgenic technology has recently received significant attention ${ }^{1,2}$. Nowadays, a variety of methods have been developed to analyze genetically modified organisms (GMO), such as polymerase chain reaction (PCR) and enzyme linked immunosorbent assay (ELISA) $)^{3,4}$. Enzyme linked immunosorbent assay was widely used with simple sample preparation, high sensitivity and specificity. However, the complex operation and extreme conditions (such as temperature and $\mathrm{pH}$ ) affected the application of ELISA. Polymerase chain reaction, as a traditional method for DNA detection and genetic analysis, had disadvantages of false positive results and nonspecific amplification. In addition, many other techniques such as electrochemical technique and fluorescence technique, because of being simple, inexpensive, reliable, sensitive and selective for genetic detection, have been widely concerned ${ }^{5,6}$.

In particular, nanomaterials have attracted considerable interests in electrochemical DNA detection ${ }^{7-9}$. It was well-known that carbon nanotubes (CNTs) were most widespread nanomaterials nowadays, which included single-walled carbon nanotubes (SWNTs) and multi-walled carbon nanotubes (MWCNTs). The carbon nanotubes (CNTs) showed many advantages of unique chemical, mechanical, electronic and thermal properties, which enabled CNTs as platform to be deve- loped for detection in various electrochemical genosensors ${ }^{10-12}$. For example, a DNA biosensor based on self-assembly of CNTs was fabricated by Wang et al. ${ }^{10}$ and Ma et al. ${ }^{11}$ also modified gold electrodes with CNTs twined by ssDNA for DNA detection. In a similar report, Cheng et al. ${ }^{12}$ successfully detected DNA of Mahathir fish with CNTs doped chitosan. However, these methods usually immobilizing MWCNTs on gold electrodes with electrostatic interaction had intrinsic limitation on sensitivity, because MWCNTs linked with DNA probe could not be fixed on gold electrode stably. Moreover, compared to traditional electrochemical sensors with only MWCNTs or gold nanoparticles, this biosensor bonding with MWCNTs and gold nanoparticles covalently enlarged response signal and enhanced the accuracy and sensitivity of detection, which was due to that gold nanoparticle as the transducer like MWCNTs also amplified and translated DNA hybridization into a directly detectable electro-chemical signal ${ }^{6}$. All these advantages impelled us to believe this bisensor would perform well on detecting genetically modified organism.

Herein, we demonstrated a strategy for constructing the DNA biosensor by a covalent self-assembly process as shown in Scheme-I. For this approach, the super short MWCNTs with oxidative treatment and modified by thio groups were stabilized onto the surface of Au electrode by covalent Au-S bonds. Afterwards, the gold nanoparticles (GNPs) were chemically 


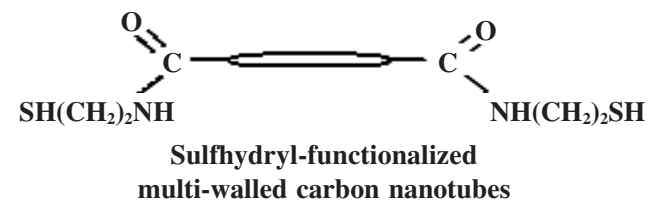
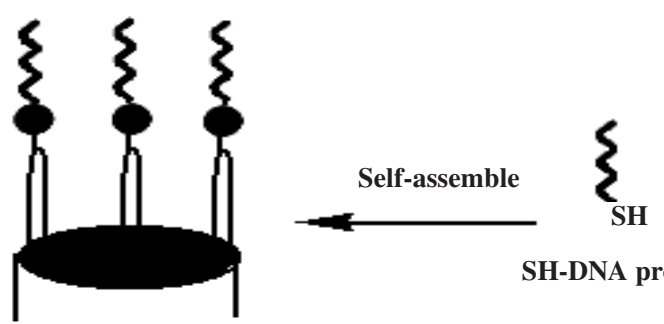

SH-DNA prober

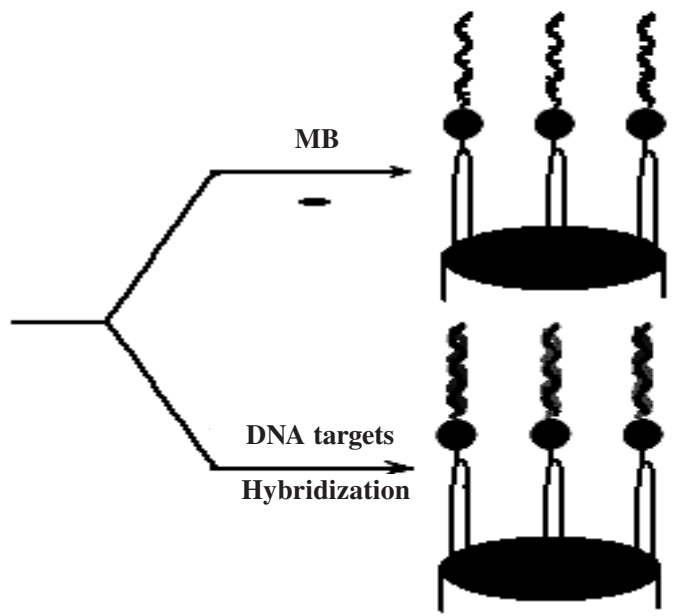

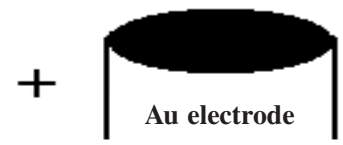
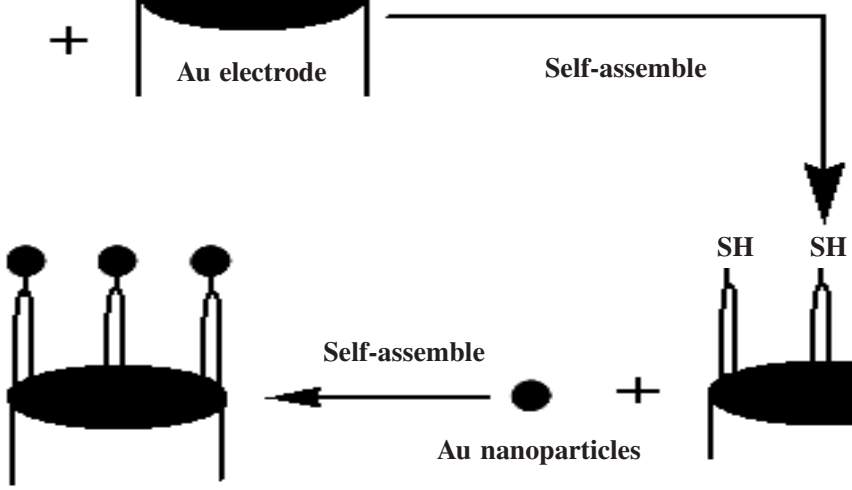

Au nanoparticles
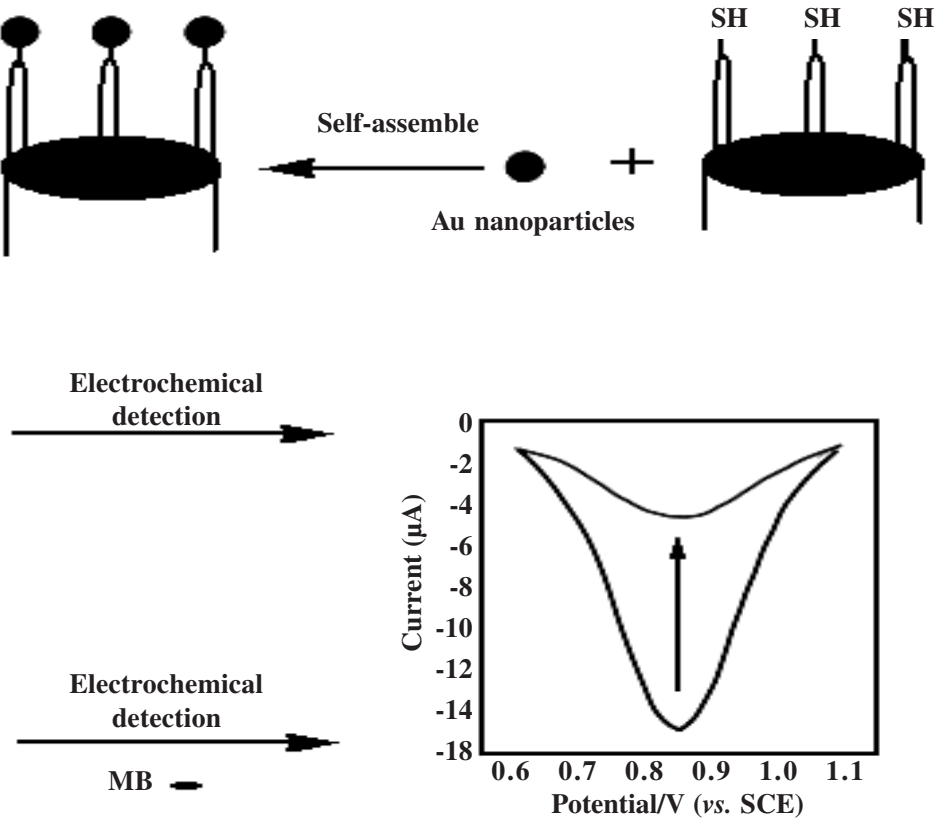

Scheme-I: Schematic representation of procedures for self-assembly of sulfhydryl-functionalized multi-walled carbon nanotubes and gold nanoparticles on the gold electrode and DNA sequence detection of genetically modified organisms

adhered to the surfaces of MWCNTs-SH. Finally, the probes, single stranded DNA (ssDNA) oligonucleotides were covalently immobilized onto gold nanoparticles via Au-S. The selfassembly processes were examined by cyclic voltammetric (CV) and the DNA detection was confrmed by the changes in the voltammetric peak of the methylene blue (MB) as a hybridization indicator.

\section{EXPERIMENTAL}

DNA base sequences of genetically modified corn were as follows: Thiolated DNA sequence: 5'-HS- $\left(\mathrm{CH}_{2}\right)_{6}$-TGG AAG TCT GTC GCG TGG AC-3', Complementary DNA target: 5'GT CCA CGC GAC AGA CTT CCA-3', Single-complementary DNA target: 5'-GT CCA CGC GAC GGA CTT CCA-3', Non-complementary DNA target: 5'-AG GAC ACG CTT GCC GTC GAC-3', All DNA oligonucleotides stock solutions were prepared with Tris- $\mathrm{HCl}(10 \mathrm{mmol} / \mathrm{L}, \mathrm{pH} 8)$ and stored in a $-80{ }^{\circ} \mathrm{C}$ freezer for further use.

Multi-walled carbon nanotubes (95\% purity) were obtained from the Chinese Academy of Sciences, Chengdu Institute of Organic. 1-ethyl-3-(3-dimethylaminopropyl) carbodiimide hydrochloride $(\mathrm{EDC} \cdot \mathrm{HCl}$ ) from Fluka (USA). Other reagents were analytical reagent grade. All chemicals were used without further purification and all solutions were prepared using double distilled water.

FT-IR spectroscopy was obtained using a FTI-650. Cyclic voltammetry $(\mathrm{CV})$ and differential pulse voltammetry (DPV) techniques were used with a LK2010A electrochemical analyzer (Tianjin) with a three electrode system. The probe DNA/gold nanoparticles/SH-MWCNTs/Au electrodes or bare electrodes were used as the working electrodes. A saturated calomel electrode (SCE) was used as a reference electrode and a platinum wire acted as an auxiliary electrode. All measurements were carried out at room temperature.

Pretreatment of multi-walled carbon nanotubes: The multi-walled carbon nanotubes were purified and functionalized with carboxyl based on the method described elsewhere ${ }^{13}$. Briefly, $60 \mathrm{mg}$ of purified MWCNTs were dispersed in $48 \mathrm{~mL}$ of 3:1 (volume) mixture of concentrated $\mathrm{H}_{2} \mathrm{SO}_{4}$ (98 wt \%)/ $\mathrm{HNO}_{3}(16 \mathrm{M})$. Then, the mixture was stirred in reflux condition for $24 \mathrm{~h}$. After cooling to room temperature, the solution suffered from filter to give some precipitation (MWCNs$\mathrm{COOH}$ ). Subsequently, the MWCNs-COOH was washed several times with double distilled water until the $\mathrm{pH}$ of the solution reached about 7. Finally, the MWCNs-COOH was dried in a vacuum over $24 \mathrm{~h}$ at $40^{\circ} \mathrm{C}$.

Functionalization of multi-walled carbon nanotubes: After the pretreatment, the super short MWCNTs-COOH was functionalized with sulfhydryl ${ }^{14}$. Briefly, the MWCNTs-COOH and mercapto-ethylamine were immersed in a freshly prepared ethanol suspension containing 1-ethyl-3-(dimethylaminopropyl)carbodiimide hydrochloride (EDC) and then stirred for $24 \mathrm{~h}$. at room temperature. After that the sulfhydryl groups (-SH) were modified to the end of carbon nanotubes. Finally, the 
homogeneously suspended solution of MWCNTs-SH was usually stored at room temperature for further use.

Fabrication of biosensor: The electrode modified by SHMWCNTs (SH-MWCNTs/Au electrode) was prepared by casting $10 \mu \mathrm{L}$ of $1 \mathrm{mg} / \mathrm{mL}$ dispersion of MWCNTs-SH on the surface of the Au electrode. After $3 \mathrm{~h}$ self-assembly, the gold nanoparticles solution ( $10 \mu \mathrm{L}, 16 \mathrm{~nm}$ in diameters) was dropped onto the surface of the SH-MWCNTs/Au electrode. The electrode modified by gold nanoparticles (GNPs/SH-MWCNTs/ Au electrode) was obtained after about $2.5 \mathrm{~h}$. Subse-quently, $5 \mu \mathrm{L}$ of $0.1 \mathrm{~mol} / \mathrm{L}$ Tris- $\mathrm{HCl}$ buffer solution ( $\mathrm{pH} 8$ ) containing ssDNA was dropped on the surface of the gold nanoparticles/ SH-MWCNTs/Au electrode and the electrode was kept under $4{ }^{\circ} \mathrm{C}$ for $12 \mathrm{~h}$. self-assembly. The resultant biosensor (ssDNA/ gold nanoparticles/SH-MWCNTs/Au electrode) was quickly and thoroughly rinsed with the $0.1 \mathrm{~mol} / \mathrm{L}$ Tris- $\mathrm{HCl}$ buffer solution ( $\mathrm{pH} 8$ ) to remove unbound DNA and then successively transferred into $25 \mathrm{~mL}$ of PBS $(0.1 \mathrm{~mol} / \mathrm{L}, \mathrm{pH} 7)$ buffer containing methylene blue. The self-assembly processes above were confirmed by $\mathrm{CV}$ techniques.

Detection of DNA sequence of genetically modified corn: The detection of target DNA was carried out through the hybridization between the ssDNA/gold nanoparticles/SHMWCNTs/Au electrode and different DNA targets (the complementary targets, the non-complementary targets and targets with a mismatching base-pair). Briefly, the electrodes were immersed in $10 \mathrm{~mL}$ of PBS $(0.01 \mathrm{~mol} / \mathrm{L}, \mathrm{pH} 7)$ containing different DNA sequences respectively under $37^{\circ} \mathrm{C}$. After 1.5 $\mathrm{h}$ incubation, the electrodes were rinsed with the Tris- $\mathrm{HCl}$ buffer solution $(0.1 \mathrm{~mol} / \mathrm{L}, \mathrm{pH} 8)$ and ultrapure water to remove the unhybridized DNA. Then, the electrodes were immersed into $25 \mathrm{~mL}$ of PBS (0.1 mol/L, pH 7) buffer containing methylene blue and incubated for $6 \mathrm{~h}$. The resultant electrodes were washed with PBS (0.1 mol/L, pH 7) and double distilled water three times. The electrochemical investigation of hybridization was carried out by DPV measurements.

\section{RESULTS AND DISCUSSION}

Characterization of MWCNTs-COOH: TEM and FTIR spectroscopy were used to confirm the formation of the short MWCNTs-COOH. According to the mechanism of oxidation ${ }^{15}$, it was indicated that the MWCNTs treated with concentrated $\mathrm{H}_{2} \mathrm{SO}_{4} / \mathrm{HNO}_{3}$ could produce more active defects and the length of MWCNTs prepared distributed from 50 to $200 \mathrm{~nm}$ [Fig. 1(A)], which enabled CNTs to provide connectors and components for molecular electronic devices ${ }^{16}$. Besides, in order to identify the MWCNTs-COOH formed above, the FTIR spectrum was shown in Fig. 1(B). Compared with raw MWCNTs, the FTIR of shortened MWCNTs had obvious absorption peaks at 1726 $\mathrm{cm}^{-1}$ and $3430 \mathrm{~cm}^{-1}$ which correspond to the $-\mathrm{C}=\mathrm{O}$ and $-\mathrm{OH}$ absorption bands. Accordingly, this demonstrated that MWCNTs with relatively more carboxylic acid groups was prepared successfully.

Optimization of self-assembly time of MWCNTs: The measurements were performed in $25 \mathrm{~mL}$ of PBS $(0.01 \mathrm{~mol} / \mathrm{L}$, $\mathrm{pH} 7$ ) at scanning speed of $50 \mathrm{~m} \mathrm{~V} / \mathrm{s}$. As shown in Fig. 2, the self-assembly of carbon nanotubes onto the bare gold electrode led to increase of the peak current and when the self-
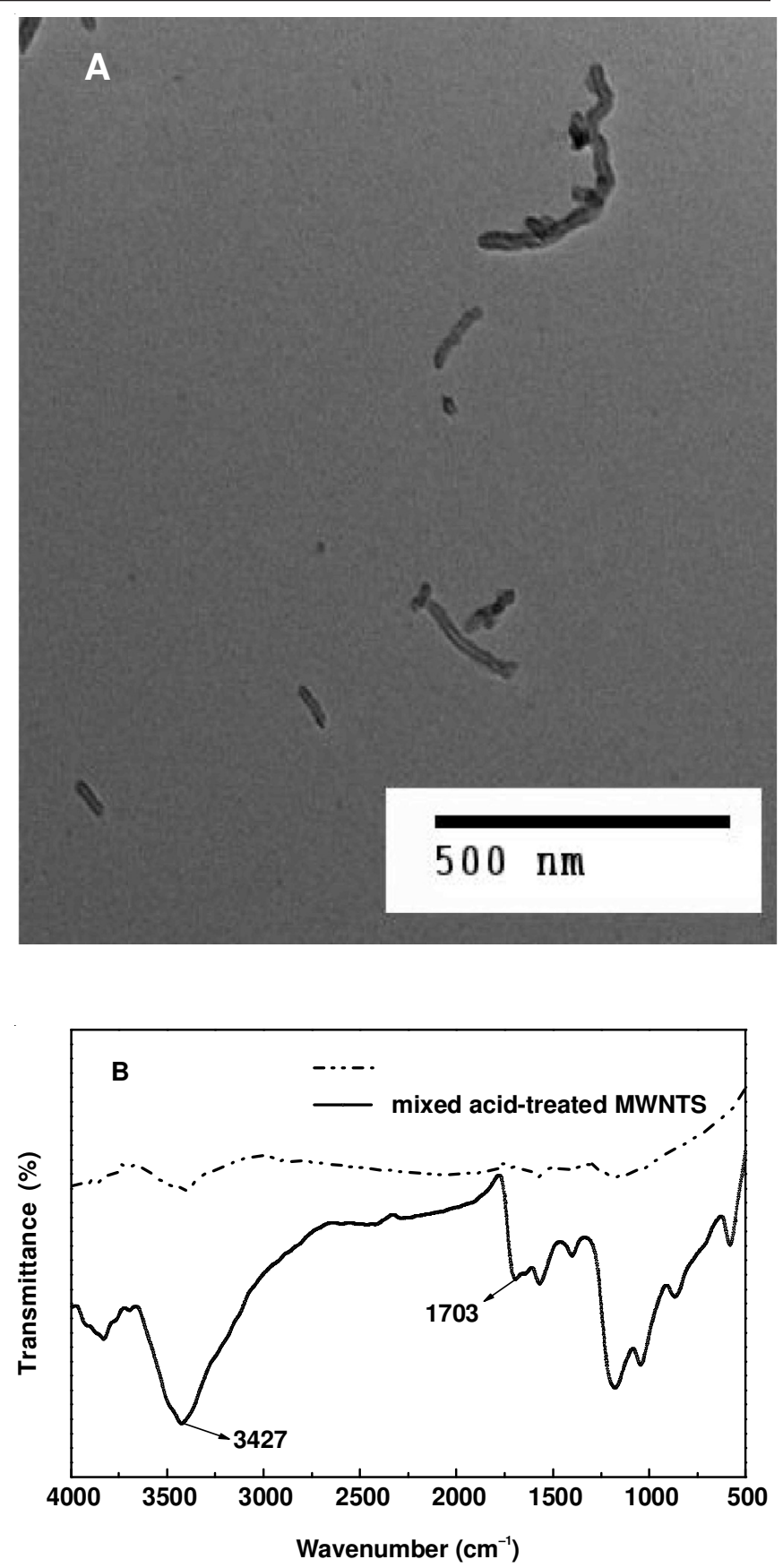

Fig. 1. (A) TEM of short MWCNTs treated with concentrated $\mathrm{H}_{2} \mathrm{SO}_{4} / \mathrm{HNO}_{3}$ ultrasonic method, (B) FTIR spectra of raw MWCNTs and mixed acid-treated MWCNTs

assembly time was less than $2.5 \mathrm{~h}$, the oxidation peak current became increasingly high with the growth of the self-assembly time, which could be attributed to that the numbers of carbon nanotubes on surface of gold electrode increased gradually. However, after $2.5 \mathrm{~h}$, the oxidation peak current declined. It could be due to that the aggregation of the carbon nanotubes increased the thickness of the carbon nanotube layer on gold electrode, which affected the transfer of electron on the surface of electrode and thus caused the decline of peak current. Therefore, $2.5 \mathrm{~h}$ of self-assembly time was chosen as the optimum time so that the optimum numbers of carbon nanotubes were fixed on the surface of the electrode and the oxidation peak current reached the highest. 


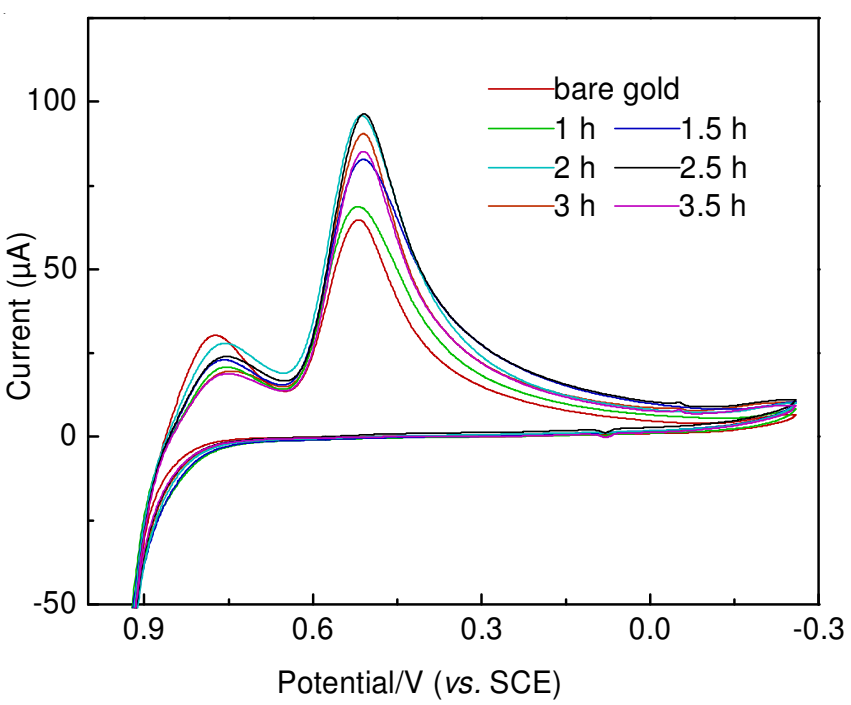

Fig. 2. CV of different self-assembly time of MWCNTs

Characterization of ssDNA/gold nanoparticles/SHMWCNTs/Au electrode: As an effective method of electrochemical characterization, cyclic voltammetry (CV) was used to study the stepwise assembly of this biosensor. Fig. 3 showed the $\mathrm{CV}$ of the electrodes with different modification during the self-assembly processes in PBS $(0.1 \mathrm{~mol} / \mathrm{L}, \mathrm{pH} 7)$ at scanning speed of $50 \mathrm{~m} \mathrm{V/s}$. Obviously, the stepwise assembly of carbon nanotubes, gold nanoparticles and probe ssDNA on gold electrode caused gradual increase of peak current and both the anodic and cathodic peak current increased regularly with the number of layers increasing from 1 to 4 layers. The excellent electrochemical performance of this biosensor was primary attributed to the significant ability of carbon nanotubes, gold nanoparticles and probe ssDNA in accelerating electron transfer, which benefited the subsequent detection of the DNA sequences of genetically modified corn. Besides, the peak current increasing or not was usually used to determine whether these substances above were assembled onto the surface of electrodes successfully and the increase magnitude of peak current could measure the amount of carbon nanotubes, gold nanoparticles and probe ssDNA assembled onto the surface of electrodes roughly.

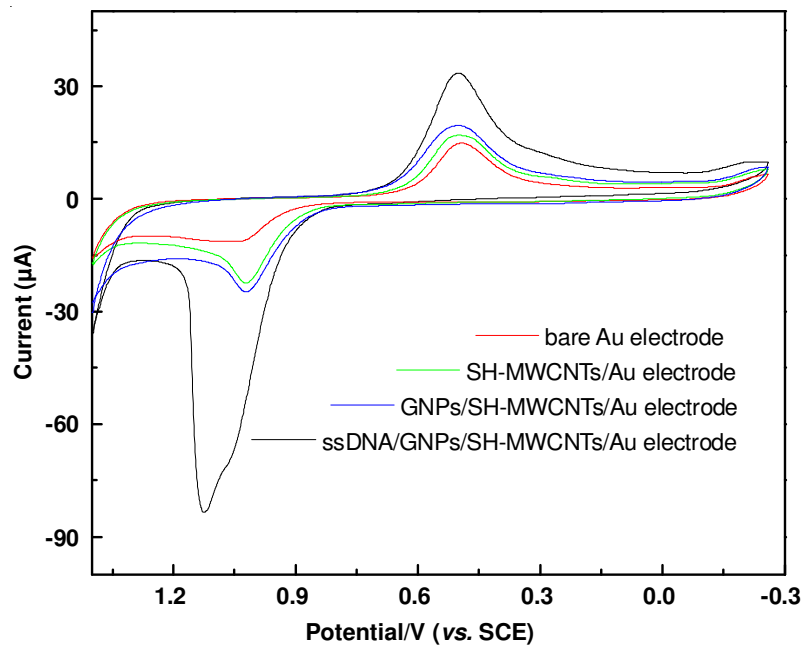

Fig. 3. CV of the electrodes with different modification during the selfassembly processes
Influence of methylene blue concentration on sensitivity: Table-1 showed that the higher or lower concentration of methylene blue caused the reduction of the relative current difference $(\Delta \mathrm{Ip})$ and when the concentration was $10^{-6} \mathrm{mmol} /$ $\mathrm{L}, \Delta \mathrm{Ip}$ was relatively highest. These indicated that an appropriate concentration of methylene blue could improve the performance of biosensor in discriminating between ssDNA and dsDNA, which enhanced the sensitivity of DNA detection. This enabled us to study the influences of the concentration of methylene blue as a hybridization indicator on the electrochemical signal.

\begin{tabular}{|c|c|c|c|c|c|}
\hline \multicolumn{6}{|c|}{$\begin{array}{c}\text { TABLE-1 } \\
\text { EFFECT OF METHYLENE BLUE CONCENTRATION } \\
\text { ON THE CURRENTS SIGNAL OF ELECTRODES } \\
\text { MODIFIED BY ssDNA OR dsDNA }\end{array}$} \\
\hline $\mathrm{MB}(\mathrm{mmol} / \mathrm{L})$ & $10^{-7}$ & $10^{-6}$ & $10^{-5}$ & $10^{-4}$ & $10^{-3}$ \\
\hline $\mathrm{Ip}_{\mathrm{ssDNA} / \mathrm{Au}}(\mu \mathrm{A})$ & -9.73 & -32.33 & -10.48 & -4.56 & -4.05 \\
\hline $\mathrm{Ip}_{\mathrm{dsDNA} / \mathrm{Au}}(\mu \mathrm{A})$ & -11.49 & -41.48 & -12.49 & -5.31 & -4.55 \\
\hline$\Delta \mathrm{Ip}(\%)$ & 18.1 & 28.3 & 19.2 & 16.6 & 12.3 \\
\hline
\end{tabular}

Effects of methylene blue adsorption time: Both cyclic voltammetry (CV) and difference pulse voltammetry (DPV) were used to study the effects of adsorption time on peak current. Fig. 4 (A) clearly shown that the increase of adsorption time was followed by the growth of the absolute value of peak current difference. When the adsorption time was $70 \mathrm{~min}$, the peak current reached the maximum and then with the adsorption time increasing to $90 \mathrm{~min}$, the peak current was no longer change nearly. Similarly, when the adsorption time was 60-70 min, the peak current difference reached the maximum [Fig. 4(D)]. This was predominantly due to that the amount of methylene blue coupled to the double-stranded DNA became more and more with the increase of the adsorption time, which caused growth of the absolute value of peak current difference. However, when the adsorption time reached a limit value, the electrostatic adsorption between the methylene blue and guanine (G) on the DNA chain reduced electrochemical activity of guanine, which led to appearance of interference peaks both on reduction peak [Fig. 4(B)] and oxidation peak [Fig. 4 (C)]. It was subsequently concluded that 50 minutes was the optimum adsorption time of methylene blue in this experiment.

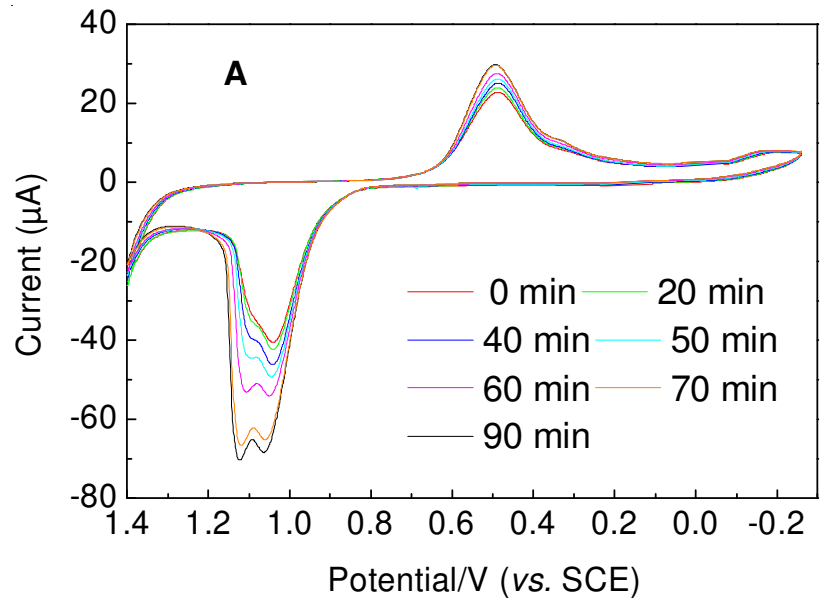



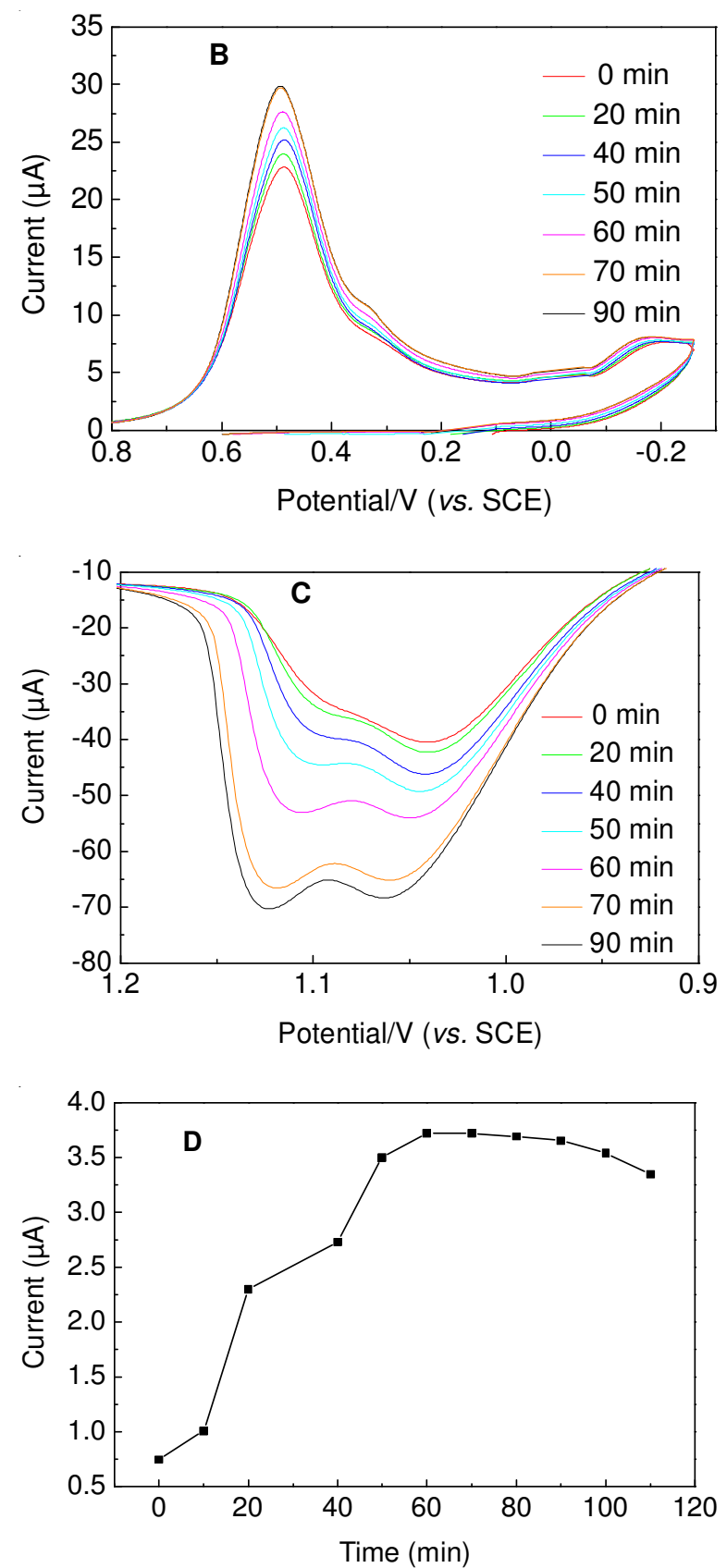

Fig. 4. (A) Peak current cyclic voltammetry in different methylene blue adsorption time, (B) Oxidation peak current cyclic voltammetry in different methylene blue adsorption time, (C) Reduction peak current cyclic voltammetry of different methylene blue adsorption time and (D) The absolute value of the peak current difference in the different adsorption time

Optimization of scanning speed: In this work, we tested the cyclic voltammogram (CV) of ssDNA/gold nanoparticles/ MWCNTs/Au electrode at different scanning rates in solution of methylene blue. Fig. 5(A) showed that the redox peak current of CV grew as the scanning speed increased. This was due to that the increase of the scanning speed made the numbers of electrons through the surface of the electrode increased and the current grew within a unit time. So, it was easier to detect the electron transfer and the current change before and after the hybridization reaction with more faster scanning speed. However, the faster scanning speed was, the more hetero peaks ware and these hetero peaks could interference the indicator (methylene blue) in the detection greatly. As shown in Fig. $5(B)$, when scanning speed reached $60 \mathrm{mV} / \mathrm{s}$, the hetero peak appeared in the range of 0.3-0.2 volts and as scanning speed up to $100 \mathrm{mV} / \mathrm{s}$, the reduction peak had hetero peaks at the potentiometers $0.25-0.15 \mathrm{~V}$ and $-0.15-0 \mathrm{~V}$. So, $50 \mathrm{mV} / \mathrm{s}$ was chosen as the optimal scanning speed of methylene blue for further detection.
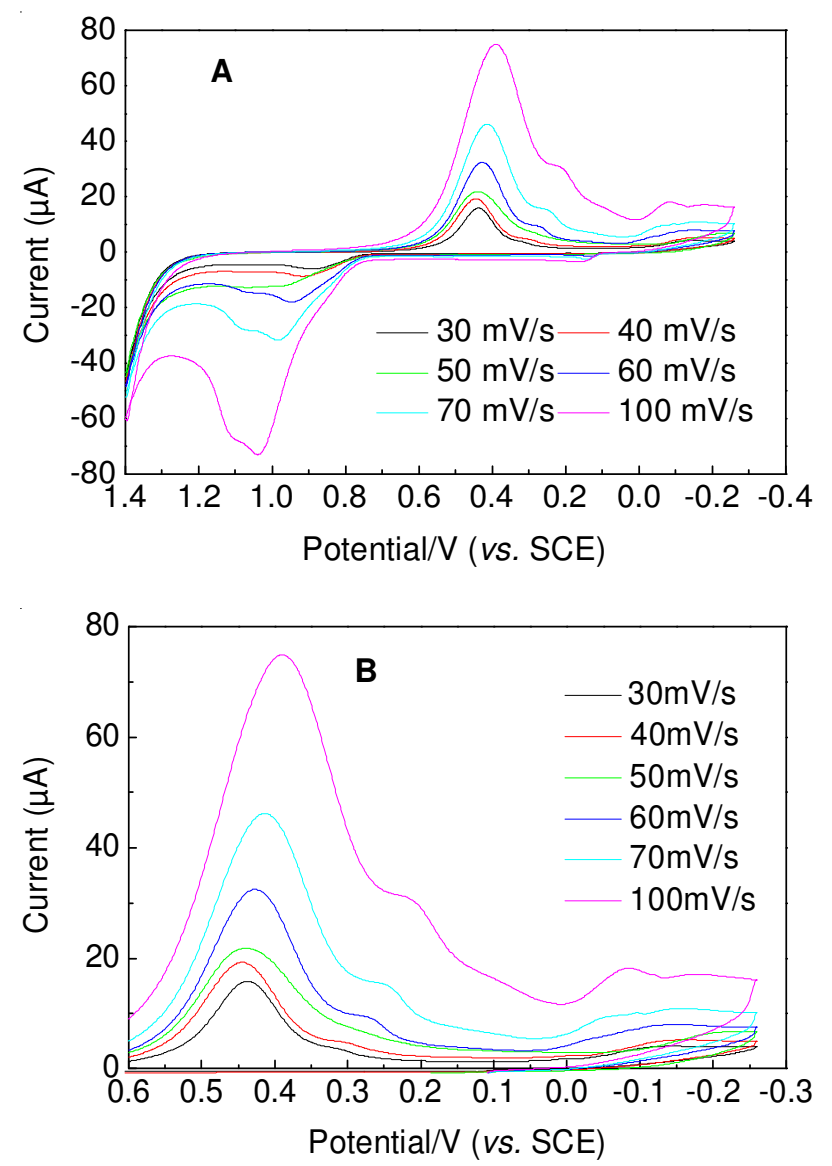

Fig. 5. (A) CV of the electrode under the different scanning speed, (B) the oxidation peak under the different scanning speed

Electrochemical detection of DNA sequences of genectically modified corn: A high selectivity is required for the detection of DNA sequences. In this work, the selectivity was evaluated by testing the response of the hybridization assay between the prober ssDNA and different targets (a): complete complementary sequence, (b): sequence with a mismatching base-pair and (c): non-complimentary sequence), respectively under optimized conditions. The results were clearly presented in Fig. 6. Since methylene blue as a cationic electrochemical indicator could interact rapidly with the ssDNA by electrostatic adsorption ${ }^{15}$, the ssDNA/gold nanoparticles/ MWCNTs/Au electrode had a lowest DPV signal [Fig. 6(d)]. And the lowest methylene blue reduction signal was obtained after the complete complementary DNA sequences hybridizing with the prober ssDNA [Fig. 6(a)]. This was predominantly attributed to reduction of methylene blue embedded into the double-stranded DNA. In contrast, when the non-complementary DNA was as target, the DPV signal of DNA/gold nanoparticles/ SH-MWCNTs/Au electrode had a little increase, which showed the high selectivity of this DNA biosensor (Fig. 6(c)). In addition, 


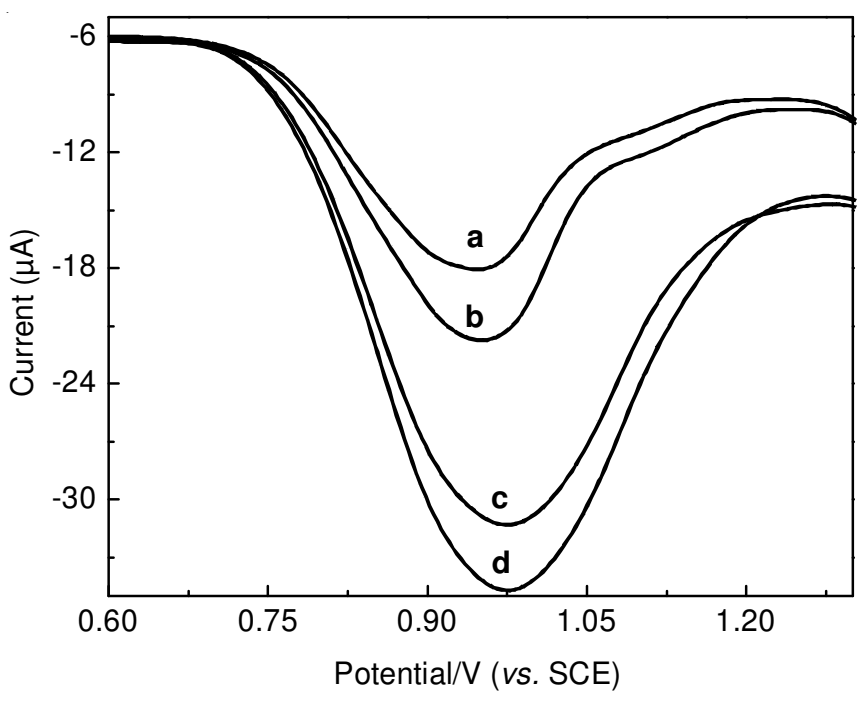

Fig. 6. DPV of (a) complementary target DNA, (b) target DNA with a mismatching base-pair, (c) non-complimentary target DNA (d) DNA/gold nanoparticles/SH-MWCNTs/Au electrode

when the one-base mismatch DNA was as target DNA, the DPV signal was higher than that of non-complimentary DNA and lower than that of complete complementary DNA [Fig. 6(b)], which also confirmed that this biosensor was capable of distinguishing the single mismatch DNA sequence.

Our further work evaluated the sensitivity of this DNA biosensor by varying the concentration of complimentary DNA targets. After the hybridization of this probe with targets, the current value obtained in the DPV response was recorded with three repetitive measurements. As shown in Fig. 7, the current response was linearly relating to the concentration of the target DNA in the range from $1.0 \times 10^{-9}$ to $1.0 \times 10^{-6} \mathrm{~mol} / \mathrm{L}$. The regression equation is expressed as eqn. 1 ,

$$
\Delta \mathrm{ip}(\mu \mathrm{A})=0.46947 \log \mathrm{C}+1.77995
$$

where $\mathrm{C}$ is the concentration of target sequences and $\Delta \mathrm{ip}$ is the DPV value. The limit of detection (LOD) is obtained as expressed by eqn. 2 ,

$$
\mathrm{LOD}=3 \times \text { S.D. } / \mathrm{r}
$$

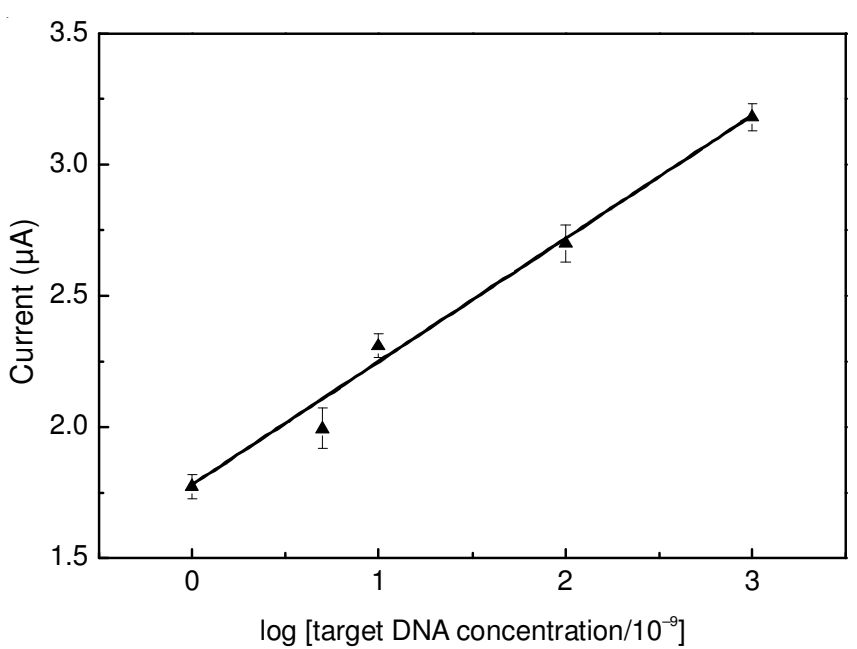

Fig. 7. DPV of different target concentrations and the resulting logarithmic standard plot where $r$ is the slope of the curve equation and S.D. represents the standard deviation for intensity of current. Accordingly, the LOD is $4.03 \times 10^{-10} \mathrm{~mol} / \mathrm{L}$, which is lower than those based on only random MWCNTs or gold nanoparticles ${ }^{10,17}$.

\section{Conclusion}

In summary, a novel detection system was fabricated by combining MWCNTs, gold nanoparticles and ssDNA with gold electrodes covalently. Under optimized conditions, the results of DPV demonstrated that this detection system had a higher selectivity. The could be due to that MWCNTs and gold nanoparticles as the transducers amplified and translated DNA hybridization into a directly detectable electro-chemical signal $^{6}$, which enlarged response signal and enhanced the selectivity of detection. This biosensor also showed easy operation, rapid detection, wild linear range and acceptable accuracy. In view of these excellent properties, the biosensor has great potential to detect DNA sequences of many other genetically modified organisms.

\section{ACKNOWLEDGEMENTS}

This work was supported by the Natural Science Foundation of China (No. 21106101, No. 21172171) and Natural Science Foundation of Tianjin (No. 12JCZDJC29500) and Youth Foundation of Tianjin (No. 13JCQNJC06300).

\section{REFERENCES}

1. H. Stein, M. Wilensky, Y. Tsafrir, M. Rosenthal, R. Amir, T. Avraham, K. Ofir, O. Dgany, A. Yayon and O. Shoseyov, Biomacromolecules, 10, 2640 (2009).

2. A. Romano, K. Raemakers, J. Bernardi, R. Visser and H. Mooibroek, Transgenic Res., 12, 461 (2003).

3. L. Petit, F. Baraige, A. M. Balois, Y. Bertheau and P. Fach, Eur. Food Res. Technol., 217, 83 (2003).

4. A.K. Mavropoulou, T. Koraki, P.C. Ioannou and T.K. Christopoulos, Anal. Chem., 77, 4785 (2005).

5. H.Y. Liu, S.M. Xu, Z.M. He, A.P. Deng and J.J. Zhu, Anal. Chem., 85, 3385 (2013).

6. X.W. Tang, S. Bansaruntip, N. Nakayama, E. Yenilmez, Y.L. Chang and Q. Wang, Nano Lett., 6, 1632 (2006).

7. S. Ravindran, S. Chaudhary, B. Colburn, M. Ozkan and C.S. Ozkan, Nano Lett, 3, 447 (2003).

8. A. Erdem, P. Papakonstantinou and H. Murphy, Anal. Chem., 78, 6656 (2006).

9. A.D. McFarland and R.P. van Duyne, Nano Lett., 3, 1057 (2003).

10. S.G. Wang, R.L. Wang, P.J. Sellin and Q. Zhang, Biochem. Biophys. Res Commun., 325, 1433 (2004).

11. Y.F. Ma, S.R. Ali, A.S. Dodoo and H.X. He, J. Phys. Chem. B, 110, 16359 (2006).

12. G.F. Cheng, J. Zhao, Y.H. Tu, P.A. He and Y.H. Fang, Anal. Chim. Acta, 533, 11 (2005)

13. S. Hahn, S. Mergenthaler, B. Zimmermann and W. Holzgreve, Bioelectrochemistry, 67, 151 (2005).

14. Z.F. Liu, Z.Y. Shen, T. Zhu, S.F. Hou, L.Z. Ying, Z.J. Shi and Z.N. Gu, Langmuir, 16, 3569 (2000).

15. J. Zhang, H.L. Zou, Q. Qing, Y.L. Yang, Q.W. Li, Z.F. Liu, X.Y. Guo and Z.L. Du, J. Phys. Chem. B, 107, 3712 (2003).

16. J. Liu, A.G. Rinzler, H.J. Dai, J.H. Hafner, R.K. Bradley, P.J. Boul, A. Lu, T. Iverson, K. Shelimov, C.B. Huffman, F. Rodriguez-Macias, Y.S. Shon, T.R. Lee, D.T. Colbert and R.E. Smalley, Science, 280, 1253 (1998).

17. H. Cai, X.N. Cao, Y. Jiang, P.G. He and Y.Z. Fang, Anal. Bioanal. Chem., 375, 287 (2003). 